Studia Slavica Savariensia 2016. 1-2. 297-306

DOI: $10.17668 /$ SSS.2016.1-2.297

Irena Krumes

(Osijek, Hrvatska)

\title{
KNJIXICA SHTIJENJA, I MOLITAVAH ZA VOJNIKE IZ 1835. U KONTEKSTU POVIJESNOG RAZVOJA HRVATSKOGA JEZIKA
}

\begin{abstract}
The paper analyses the language of a book of prayers dating from 1835 which was composed by an unknown author and intended for soldiers when attending the Holy Mass. It was written in the Shtokavian-Ikavian dialect. Beside spelling and orthographic analyses, additional emphasis is put on lexical analysis. Since the German original is unknown, the lexical analysis focuses on ecclesiastical terms and word formation. The first researches of the terms (Pridobrostivi, Vira, Posvetilište, Puti Uskersnutje, Iskernji) point to continuity and an advanced standardisation of ecclesiastical terms since the 18th century which was previously confirmed in catechisms. It is possible to prove that the booklet was translated within the Franciscan community as well as that the author was a priest who knew the soldiers living in the Slavonian area, i.e. the Military Frontier. At that time the soldiers were protecting the border to the Ottoman Empire. The booklet came into existence when Josephinism was at its peak and the state politics of the former Habsburg Monarchy managed to covertly control the work of the Church.

The research was conducted on the original which was found among Dragutin Tadijanović's literary legacy in Slavonski Brod.
\end{abstract}

Keywords: book of prayers, the Croatian language of the 19th century, lexis, ecclesiastical terms, military terms, history of the Croatian language

\section{Društveno-političke prilike u prvoj polovici 19. stoljeća}

Mali molitvenik Knjixica shtijenja, i molitavah za vojnike iz $1835 .^{l}$ nastao je u vrijeme kada su hrvatske zemlje bile u sastavu Habsburške monarhije, a u literaturi se još osjećao jozefinističko-prosvjetiteljski duh iako je car Josip II umro 1790. godine. Dokumentom Placetum regium omogućilo se Caru da nadzire crkvene zakone, državi da ograniči slobodu Crkvi i da svojim utjecajem uđe u hijerarhijsku vlast Crkve tako da je car mogao imenovati čak i biskupe. Time se Crkva podredila izravno državnoj vlasti. (LAKUŠ 2007: 68)

\footnotetext{
${ }^{1}$ Molitvenik Knjixica shtijenja, i molitavah za vojnike, pronađen je u knjižnoj ostavštini Dragutina Tadijanovića koja se popisivala 2014. godine. Trenutačno se nalazi u Slavonskom Brodu u Spomen-domu Dragutina Tadijanovića koji pripada Galeriji umjetnina Grada Slavonskoga Broda.
} 
Crkve su postale moralno-odgojne ustanove, a sakramentalna narav bogoslužja ustupila je mjesto moralnoj izgradnji podanika. Svećenici su trebali poučiti vjernike temeljnim moralnim vrednotama i poduprijeti vladara kao očinsku figuru u odnosu na podanike.(HOŠKO 2003: 240)

Prosvjetiteljstvo je odgovaralo tim ciljevima jer je pisana riječ bila najbolje sredstvo širenja znanja i prosvjećivanja kao i najdjelotvorniji način promoviranja društvenog i političkog poretka.

Onaj koji nema vjere, isticale su vlasti, ne boji se Boga, a onaj koji se ne boji Boga, ne može biti poslušan i vjeran podanik. (BATTARA 1847:24)

Crkva je bila sredstvo u rukama vladajućih i trebala je poticati božanski suverenitet vladara. U crkvenim djelima promoviralo se očuvanje postojećeg stanja kao temelj stabilnog društva, a svako narušavanje ili sumnja u takve postavke smatralo se pogubnim za društveni i politički poredak tadašnje države. Društvena nejednakost bila je prihvatljiva jer su razlike smatrane nepremostivima, a društvenu nejednakost, prema ondašnjoj literaturi, utemeljio je sam Bog. (LAKUŠ 2007: 72) Molitvenici koji su nastajali početkom 19. stoljeća odražavali su duh toga vremena kao i jezik kojim su pisani.

\section{Hrvatski jezik početkom 19. stoljeća}

Samardžija (2015: 9) smatra da se povijest hrvatskoga jezika u 19. stoljeću organski nastavlja na prethodno razdoblje. U kodifikacijskim nastojanjima u prvim desetljećima 19. stoljeća jasno se očituju dva tijeka. Prvi je uzusno kodificiranje što se odnosi na objavljivanje svjetovnih ili nabožnih književnih djela hrvatskih književnika i preradbe ili prijevode stranih, većinom njemačkih i engleskih autora. Drugi je tijek preskriptivna kodifikacija, tj. takva koja je svjesno provođena tomu namijenjenim djelima pisanima uglavnom u predslavitičkoj filološkoj tradiciji 18.stoljeća (pravopisi, gramatike, rječnici, rasprave).

Brozović (2008: 89) hrvatski jezik od početka 19. stoljeća do Preporoda razgraničava i periodizacijski smješta u drugu fazu četvrtog razdoblja, odnosno prvo razdoblje u razvoju hrvatskoga jezičnoga standarda. Brozović smatra da to razdoblje uključuje i devedesete godine 18. stoljeća jer su te godine označile svojevrsni prijelaz u drugu fazu standardizacijskog razvoja u kojem se pojavom prvih hrvatskih novina Kraljski Dalmatin javlja polifunkcionalizacija novoštokavskog hrvatskoga pismenog jezika, posebno pravne i agrikulturne terminologije (list je bio dvojezičan, talijansko-hrvatski). U to vrijeme objavljen je i prijevod Općeg građanskog zakonika koji će se odraziti na život u hrvatskim zemljama. U Slavoniji Kanižlić objavljuje svoj Kamen pravi smutnje velike (1780.) i svojom teološkom terminologijom i frazeologijom pokazuje značajke specijaliziranog jezika koji će se potvrditi i u kasnijem Katančićevom prijevodu Svetoga pisma (Budim 1831., prijevod 1815.). Iako objavljen na ikavici, svaki prijevod Biblije ima posebnu važnost za jezik toga naroda. I u tome razdoblju razvoja hrvatskoga jezika ikavsko-ijekavsko dvojstvo nije neobično iako do Preporoda sve više prevladava ijekavica zbog ponovnog utjecaja Dubrovnika. Pravopis i grafija prilično su bili ujednačeni, a razlika je u pisanju bila samo u dva 
ili tri grafema (̌̌, š, č). Vrhunac je ujednačavanja bila komisija u Zadru koja je početkom 19. stoljeća pod predsjedanjem Franje Marije Appendinija morala ukinuti postojeće razlike između dubrovačke i dalmatinske grafije, a odluke komisije postale su obvezatne i u školama u Dalmaciji.

U ovom razdoblju završava i štakavsko-šćakavsko novoštokavsko dvojstvo na štetu šćakavštine, a postoje naznake i da se kajkavci i sjeverni čakavci sve više osvrću na štokavsku pismenost. Ova faza je karakteristična po tome jer hrvatski jezik postaje iznadregionalni jezik u odnosu prema pokrajinskima, napustit će se kajkavski pisani jezik koji je bio na dobrom putu da postane standardni jezik, gramatička i glasovna norma još je neusklađena (BROZOVIĆ 2008: 81). Preporod je naime važniji u kulturnom, društveno-političkom i općenacionalnom smislu, ali u čisto jezičnom pogledu Preporod znači samo dvoje: proširenje već postojećeg novoštokavskog pismenog jezika u teritorijalnom i funkcionalnom smislu, i drugo, reformu grafije, uz stvaranje uvjeta da ta nova grafija ubrzo postane općehrvatskom (BROZOVIĆ 2008: 86).

Priručnici, pravopisi i gramatike imaju kodifikacijsku vrijednost, a u ovom se razdoblju tiskaju u velikom broju pa tako Voltiggi tiska rječnik Ričoslovnik 1803, od 1801. izlaze Stullijevi rječnici tiskani slavonskom grafijom, Franjo Maria Appendini tiska Grammatica della lingua illyrica 1808., a Šime Starčević prvi put donosi četveronaglasni sustav u svojoj gramatici Nova ricsoslovica iliricska 1812. Nešto kasnije pridružuje im se i Ignjat Brlić sa svojom gramatikom na njemačkom jeziku Grammatik der illyrischen Sprache 1833. On će 1836. prihvatiti Gajev prijedlog o bilježenju jata s rogatim ě kao i bilježenje vokalnog e sa ér.

Peto razdoblje (prema Brozoviću) u razvoju hrvatskoga jezika počinje objavom Gajevog Pravopisza 1835. u Danici.

Moguš je primijetio da i dubrovački leksikografi i gramatičari početkom 19. stoljeća uzimaju podatke iz desetak djela slavonskih pisaca. Približavale su se književne stilizacije štokavskog juga i štokavskog sjevera kao i grafemsko približavanje. U prvim desetljećima 19. stoljeća novoštokavština je književno stilizirana na širokom prostoru od Slavonije preko Bosne do Dubrovnika i od Dubrovnika do Like. (MOGUŠ 2009: 144)

Barbara Oczkowa (2010: 240) u svojoj knjizi naglašava da je proces standardizacije hrvatskoga jezika od 1700 . do 1836 . već dosta uznapredovao. Nakon selekcije (izbora) i deskripcije (opisa), nalazi se u procesu kodifikacije (propisa) i elaboracije (obrade). Gramatička norma nije u potpunosti stabilizirana npr. posljednja etapa sinkretizma padeža. Hrvatski jezik je interdijalekt utemeljen na dugoj književnoj tradiciji s prevagom obilježja zapadne novoštokavštine te $\mathrm{s}$ ustaljenom pisanom normom i opisom naglasne norme (Starčević). 


\section{O molitveniku Knjixica shtijenja, i molitavah za vojnike iz 1835.}

Molitvenik ${ }^{2}$ određuje ili čini: forma, sadržaj i čitatelj (prema ŠUNDALIĆ 2003: 13). U formalnom pogledu radi se o zbirci kratkih tekstova međusobno povezanih zajedničkom temom. To je zbirka tekstova i molitava koja ne traži kontinuirano čitanje, nego čitatelj odabire tekst za čitanje prema vlastitom nahođenju, a izbor je određen prigodama i vremenskim odrednicama zbiljskoga života. Sadržaj molitvenika uvijek je molitveničkog karaktera, u duhu kršćanske teologije u kojem su suprotstavljeni život i smrt. Na tragu toga karakter tekstova počiva na figuri antiteze. Čitatelju je najčešće dodijeljena pozicija grješnika ili potencijalnog grješnika kojemu tekstovi molitvenika mogu pomoći na putu vjerskog pročišćenja.

Knjixica shtijenja, $i$ molitavah za vojnike, 1835. namijenjena je vojniku za individualno čitanje. Na početku se knjižice autor obraća vojnicima u množini. Osnovni ton teksta je didaktičan, savjetodavan u prvom dijelu, a zagovara pokornost ne samo Bogu nego i caru. Pisac poznaje vojnički život i probleme, u molitveniku ne postoji izbor brevijarskih tekstova i prvi tekst ne sadrži mnogo crkvenih naziva.

Molitvenik je po opsegu malen, nema 200 stranica, a autor je vjerojatno svećenik fratar što se može dokazati na osnovu jezikoslovne analize, kao i jezika i rječnika kojim se koristi.

Knjižica je prevedena $s$ njemačkog originala, a tiskana $u$ Budimu što nas navodi da je prevoditelj pripadnik „budimskog kruga“. Knjižica je pronađena u privatnoj knjižnici našega književnog barda Dragutina Tadijanovića prilikom popisivanja njegove knjižne ostavštine.

Ovaj je molitvenik u prvom redu namijenjen vojnicima jer u prvom dijelu govori o vojničkoj službi i kako ona nadopunjuje službu božju. Promiče ideju da vojnik može istovremeno biti dobar vojnik kao i kršćanin. Svaki vojnik mora biti bogobojazan, iskreno tražiti duhovno spasenje, biti lojalan caru i slušati svoga vladara.

Nakon uvodnog dijela koji se obraća svim vojnicima tekst prelazi u obraćanje jednom vojniku čitatelju i niže savjete za život vojnika u kojima se afirmira rad, vjernost, sloga, zadovoljstvo. Potom molitvenik govori vojniku o izdaji i teškim posljedicama toga čina, o čistoći tijela i molitvama koje svaki vojnik mora učiniti u jutro i večer. Religioznim tonom govori o krjepostima vojnika i što bi trebao raditi prije, a što poslije Svete Mise. O molitvama nešto više objašnjava u dijelovima o molitvi prije jela i poslije, prije ispovijedi, kako moliti pokajanje, kako moliti prije pričešćenja i poslije. Potom autor prelazi na pojašnjenje Vjerovanja i govori o svrsi života čovjeka i duhovnom spasenju.

${ }^{2}$ Molitvenik je zbirka molitava, tekstova, pjesama, čija struktura može imati karakter promjenjivosti ili ustaljenosti, a namijenjen je privatnoj pobožnosti ili javnoj službi Božjoj, bilo pojedinca bilo zajednice vjernika. (ک̌SUNDALIĆ 2003: 18) 
O Božjim zapovijedima, crkvenim, milostima Božjim, o sakramentima, o dobrim djelima, o molitvi, grijehu i pokori piše u nizu u kojem se obraća vojniku toplo i prijateljski. Tumači mu čistilište, nebo i pakao.

U završnom dijelu knjižice sadržane su molitve i među njima je prva za cara, vojsku prije pogibije i poslije, molitva na putu, molitva prije bitke, zahvalna pjesma i pjesma Mojsijeva i naravno molitva umirućega.

U malom dodatku koji je posebno zanimljiv spominje vojničku zakletvu i važnost straže na Savi.

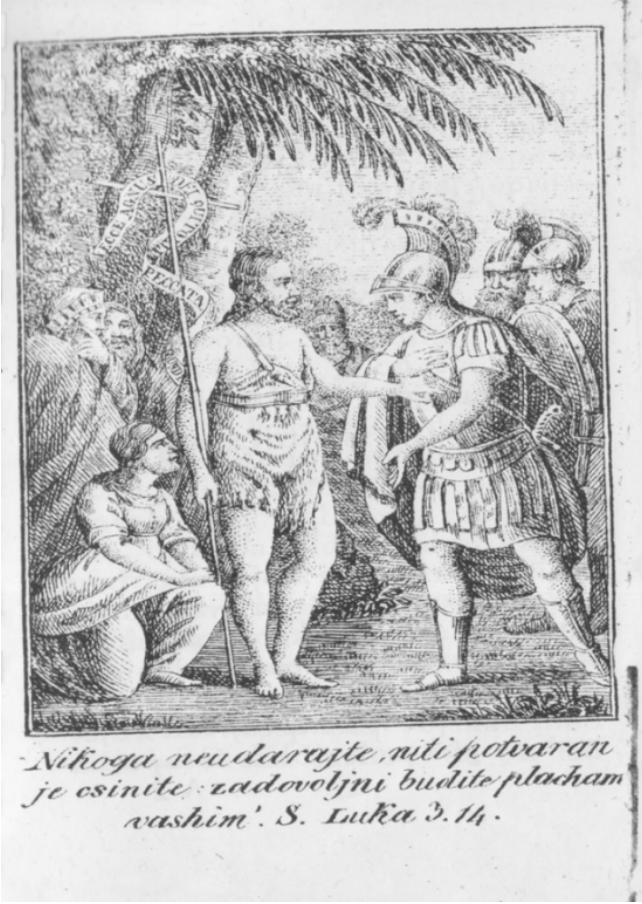

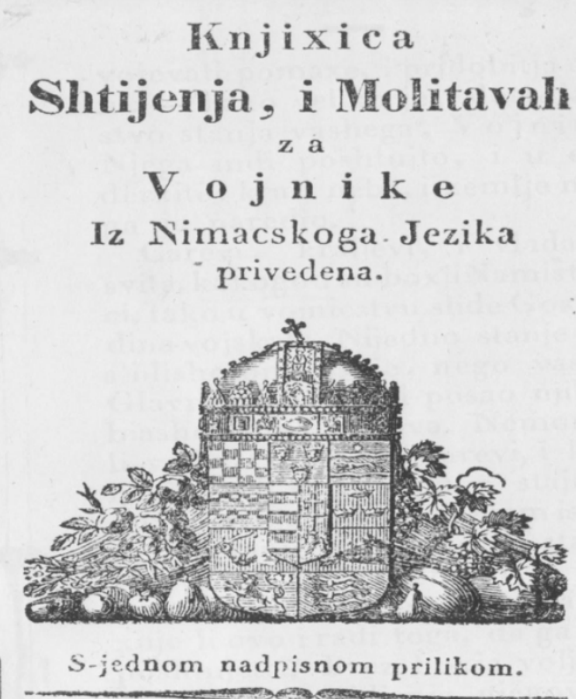

U BUDHTE 1835.

Tiskopisom Iv. Gyuriana, i M. Rago.

Slika 1. Naslovnica molitvenika Knjixica Shtijenja, i Molitavaha za Vojnike iz Nimacskoga Jezika privedena iz 1835.

\section{Jezik molitvenika - nastavak franjevačke jezične koine iz 18. stoljeća}

Nepoznati autor molitvenika za vojnike napisao je prijevod sa izvornika na njemačkom jeziku. Takvi molitvenici bili su uobičajeni u okviru Habsburške monarhije. No ovaj autor koristi jezik koji možemo identificirati kao nastavak franjevačke jezične koine iz 18. stoljeća. Pisan je štokavicom i to ikavicom, no ponegdje se mogu uočiti ikavsko/jekavske dvojnosti. Jezik je obično određen jezikom pisca-uzora, piščevim podrijetlom, a ponegdje i govornom pripadnošću publike kojoj je tekst namijenjen (GABRIĆ-BAGARIĆ 2007: 137). Zato je potrebno pomno analizirati sve jezične razine kako bismo mogli pouzdano odrediti radi li se o franjevačkoj jezičnoj koine iz 18.stoljeća. 


\section{Slovopis}

Slovopis molitvenika gotovo je identičan slovopisu fra Marijana Lanosovića u njegovoj gramatici: $\mathrm{cs}=\breve{\mathrm{c}}, \mathrm{ch}=\mathrm{c}, \mathrm{gj}, \mathrm{dj}=\mathrm{d}, \mathrm{cx}=\mathrm{dž}, \mathrm{sh}=\check{\mathrm{s}}, \mathrm{x}=\check{\mathrm{z}}, \mathrm{er}=\mathrm{r}($ TAFRA 1985: 183)

U našem molitveniku otkrivamo sljedeći slovopis: $\mathrm{cs}=\check{\mathrm{c}}$, Csesto, pocsetak, vojnicski, macs, nimacski, $\mathrm{lj}=1 \mathrm{j}$ nazivlje, upotribljava, $n \mathrm{j}=\mathrm{nj}$ Shtjenje, $\mathrm{sh}=\breve{\mathrm{s}}$ sloboshtina, nash, $\mathrm{t} \mathrm{j}=\mathrm{c}$ platja, sritja ( $\mathrm{kad}$ je vidljivo da je od $\mathrm{t}), \mathrm{t} \mathrm{j}=\mathrm{t} \mathrm{j}$ pridobitja, $\mathrm{ch}=\mathrm{c}$ izichi, obechaje, $\mathrm{x}=\check{\mathrm{z}}$ pruxiti, prixalostan, xivot, št $=\mathrm{cs}+\mathrm{s}$ izdajnicsstvo, $g j$ $=đ$ angjeli, hodjashe, $\mathrm{cx}=\mathrm{dž}$ kavgacxija

Prema ovom slovopisu točno se može odrediti da on pripada slavonskoj grafiji ${ }^{3}$ u cijelosti što znači da je i autor pripadnik slavonske franjevačke skupine.

Samoglasno er najpogerdnije, merzi nalazimo i kod mnogih autora franjevaca npr. Jakobovića, Bačića, Vilova, Kesića, Kanižlića, Pavića, Relkovića, Tadijanovića, Rapića, Blagojevića, Kneževića, Lanosovića, Velikanovića...

Ne piše j između samoglasnika: sviu (9), nesmie (10), ali piše j u primjerima daje (9), koje (24). Mikalja piše j u zamjenicama (GABRIĆ-BAGARIĆ 2010: 46). Obilježje franjevačkih autora je da ne pišu j između samoglasnika.

\section{Pravopis}

Akcenatske se cjeline u molitveniku pišu zajedno (vezivanje enklitika i proklitika): Neukida, nesmeta, nemoresh,neudarajte, neocsitovati,nemoxe, ali raduj se piše odvojeno što nije uobičajeno za franjevačku koine.

Prijedlog s se piše: s-live (48), s-krova (47), sa-sinovskom (59), sh-njom (60) sh-njima (50).

Ovakvi primjeri nisu ustaljeni, a zabilježeni su kod fra Jaića u obliku s'. Pojavili su se i kod Bandulavića koji je prvi uveo takav tip oznaka (GABRIĆBAGARIĆ 1989: 58) U primjeru brez obrazan vidi se da se neki pridjevi pišu s razmakom. U primjeru Oddaje uočavamo udvostručene suglasnike što je utjecaj njemačkoga jezika. Javljaju se iza kratkoga sloga, označavaju kraćinu samoglasnika ispred njih isto kao i u primjerima: Illi, alliti, millost. Velikim slovom u molitveniku piše Cesar, Kralj, nazivi se pišu velikim slovom kao i sve što se odnosi na Boga: Bog, Boxii.

Autor se drži korijenskog pravopisa pa zato nalazimo: podpuno, izkorenio, izpija. Strukovne nazive piše velikim slovom: Garnizon, Kerstjanin.

Nema bilježenja sekundarne jotacije: sritjan (66) , zasitjeni (89), platja (8)

Primloge (50), zlamen poshtenja (26) odlika je specifične fonološke skupine iz književne tradicije, a to su skupine $\mathrm{zl} \mathrm{i} \mathrm{ml}$.

Ne piše dosljedno h: kerke kosti (54) umjesto krhke kosti.

Refleks glasa jat bilježi kao i: udiliti, tilo, vridnost, bixanje, uvik, vrime. po čemu se vidi da se radi o štokavskoj ikavici.

\footnotetext{
${ }^{3}$ Slovopis se odredio prema popisu grafija koje je učinila Loretana Farkaš u svojoj knjizi Od slovosloxnosti slavonske, Osijek, 2010.
} 


\section{Morfonologija}

Izostajanje sibilarizacije u DL jd. imenica ženskoga roda e-vrste: ...u priliki braniti... (26), ...u ruki tvojoj... (48), ...u ovoj odluki ostanem... (108).

U 19. stoljeću to je bilo prihvatljivo.

Imenice $\mathrm{D}=\mathrm{L}=\mathrm{I}$

D mn. ...tvojima Cerkvenima sluxiteljima ostavio..(118)

L mn. ama/ima

Daj mi utishenje, $i$ usterpljenje u protivshtinama, pomnju, $i$ nastojiteljstvo $u$ duxnostima moga stanja...(60)

I mn. ..med vojnicima hodjashe...(4)

D mn....kojim samo neprijateljima morash strahovit biti (22)

Izjedančavanje $\mathrm{D}=\mathrm{L}=\mathrm{I}$ počelo je još u 17 . stoljeću. $\mathrm{U}$ ovim primjerima vidljivo je da su se množinski padeži izjednačili.

Imenička sklonidba $\mathrm{G}$ mn na -ah

...tako se pouzdano ufam sviu mojih grihah odpushtenje dobiti. (90)

...koliko sam putah iskernjega moga uvridio (90)

Ti si bio svidok mojih prigrishenjah, budi mi u pomochi tvojim medjugovorenjem (98)

Genitiv množine ženskoga roda propisuje i Šime Starčević u Novoj Ricsoslovici Ilircskoj 1812.

On isti naredjivah vojevati; i pokazah se kao Gospodin vojskah (A2)

Vojskah je genitiv mn. završava na -ah, ali imperfekt glagola naredjivah i pokazah u 3.1. jd. umjesto -aše ima nastavak -ah za prvu osobu jednine. Funkcionalna uloga ovoga nastavka je stilistička.

Participi sadašnji postaju pridjevi i sklanjaju se. ... s neba padajuchim (4), Terpechega Joba, grishnika pokoru csineshega... (Jaić) Uporaba participa je obilježje franjevačke književnosti. Participske su konstrukcije sinaktički utjecaji grčkoga i latinskoga jezika. U molitveniku nisu česti jer se radi o prijevodu $\mathrm{s}$ njemačkoga jezika.

Evo bo istinu si ljubio.. (101) bo, Pisano bo jest. (18)

Rječca bo je staroslavenskog podrijetla, dolazi samo u značenju naime (nije veznik).

Glagol se u rečenicama najčešće nalazi na kraju:

Tebi sam samomu sagrishio, i zlo sam prid tobom ucsinio. (100)

\section{Imenica u A + ucsiniti}

U molitveniku česte su rečenične konstrukcije: za moje poboljshanje ucsiniti (63), potvaranje ucsiniti (1), prijatnost, i ljubav ucsiniti (11), kripostna, i spasena ucsiniti (66). 
Ova rečenična konstrukcija $u$ kojoj se imenica u akuzativu nalazi prije glagola učiniti je vrlo česta. Kombinacije s glagolom činiti nisu neuobičajene za franjevačku koine.

\section{Tvorba superlativa pri-}

U tvorbi pridjeva nalazimo najplodniji prefiks pri- : Pridobrostivi (59), Privisoki (16), Primilostiv (13), Otcse priljubezni (59), primudra volja (60).

Prefiks pri- javlja se u tvorbi opisnih i posvojnih pridjeva, a tvori se od pridjevske osnove. Prefiks pri- nosi značenje kao danas prefiks pre-, odnosno iziriče svojstvo najvećeg stupnja od onog izrečenog osnovnim pridjevom. Ovo pravilo o tvorbi superlativa na ovakav način moguće je pronaći u kratkoj gramatici Della Bellina rječnika Dizionario gdje stoji: Superlativi u hrvatskom jeziku nemaju vlastitoga nastavka već se tvore dodavanjem pripozitivu...(DELLA BELLA 1728: 45)

I ako se ne bi nahodio medju katolicima, tvoj zakon nishtanemanje poshtuj, i u svakoj prigodi pokaxi se, koje si Vire...

Nishtanemanje (12) prilog čije potvrde možemo naći u kontinuitetu kod svih franjevaca, a zanimljivo je čak i do 1845. u autora Nemčića i djelu "Putositnice".

Ako sluxbu tvoju virno, $i$ vruchoxeljno iz ljubavi prama Bogu, i Cesaru csinish, tako tvoja sluxba jest sluxba boxja.

Vruchoxeljno (12) je prilog čiju uporabu često nalazimo kod franjevačkih pisaca.

\section{Crkveno nazivlje}

U cijelom molitveniku povremeno se pojavljuje crkveno nazivlje, a među njima najbrojnjije je ono najraširenije i danas: Cerkva (25), Kerstjanin (42), nazivi za Boga i Isusa: Gospodin (61), Branitelj (60), Istina (67), Mudrost (67), Isus (61), Angjeli (61), Bogorodica (66), Evangjelje (66), Duh Sveti (66), Sin Isukerst (66), Sveta Vecsera (70), nazivi vezani za obred: Posvetilishte (70), Misnik (71), Missa (71), Podizanje (81). Većina ovih naziva je staroslavenskog podrijetla.

Kontinuitet u leksiku - 18.st.

Prema značenju pojedinih crkvenih naziva moguće je dokazati da se nazivlje ne tvori kao novotvorenica, nego se koristi u kontinuitetu prema uzoru na starije autore: iskernji (11) 'bližnji', vruchoxeljno (12) 'zdušno', posvetilište (11) 'dio oltara', shkodljiva pomanjkanja 'nedostaci, mane, grijesi' , sobstvo (26) 'osoba, osobnost, biće', pedepsanje (32) 'kažnjavanje', usterpljenje (42) 'strpljenje', nenavidost (44) 'mržnja, zloba, zavist', Pridobrostivi Boxe! (62) 'predobri Bože'. Isto nazivlje koriste Velikanović, Bačić, Kanižlić.

Primjeri kao fala, dika, hasna - nisu dijalektizmi nego uobičajene riječi početka 19.st. baštinjene od 18.st. 


\section{Sinonimija}

Sinonimija i uvođenje sinonimnih parova u prozni tekst obilježje je norme franjevačkih pisaca 18. stoljeća ${ }^{4}$. Pojava sinonimije nije ništa novo u hrvatskoj književnosti jer se pojavljuje još od srednjovjekovnih litrugijskih tekstova, nalazimo je i u leksikografskim djelima (Mikalja ${ }^{5}$ ), a naročito je uočljiva u pojavi kontaktne sinonimije. ${ }^{6}$ U ovom molitveniku sinonimija se uglavnom javlja u nazivlju između domaće riječi i njezine strane istvrijednice: Na Slavu, illiti Gloria (74), Na Virovanje, illiti Credo (76), Na Priglasje,ili Praefatio (79), Ocsistishte, ili Purgatorium (141), Sakramenti, ili njegovo Sveto Ime (123).

Sinonimija se javlja u tragovima i među općim imenicama: Bolnice, iliti shpitali (54), tridesetine, ili harmice (182).

Sinonimni par uvijek ima sličnu strukturu istoznačnica + veznik iliti, ili + istoznačnica. Usporedno navođenje dva leksema u sinonimnom odnosu povezanih veznikom ili, iliti, je leksičko-semantički (i stilski) postupak poznat još iz glagoljskih neliturgijskih tekstova 15 . stoljeća ${ }^{7}$. Javlja se u većine franjevačkih pisaca (Kanižlića, Velikanovića, Bačića...).

\section{Vojno nazivlje}

O vojnom nazivlju nema dovoljno podataka iz starijih religioznih tekstova, a u molitveniku namijenjenom vojnicima moguće je očekivati veći broj takvih naziva: Officir (31), Zapovidnik (31), Garnizon (24), bitva (162) 'bitka', vojak (19), ratobojna sluxba (20), Regimenta (39), ukvartiljit (20), novak (41).

Kao i u crkvenom nazivlju pojava sinonimije nije ništa neobično jer se uporedo koristi domaća riječ i posuđenica: Kordon, iliti Rastava (181), Stotinik, ili Kapitan (8), Pribivalishte, illiti kvartir (24).

\section{Zaključak}

U molitveniku je prepoznatljiv utjecaj franjevačke jezične stilizacije na novoštokavskoj osnovi i ikavici. Prema jezičnim osobitostima uočljivo je približavanje standardu na svim jezičnim razinama i prihvaćanje svih obilježja franjevačke jezične stilizacije. Odabir novoštokavštine, bilježenje jata, crkvena terminologija i sinonimija u nazivlju samo su neke od zajedničkih osobina $\mathrm{s}$ franjevcima. Jedina iznimka je da se ne čuvaju stari padeži, $D=L=I$. i izostanak sibilarizacije u DL jd. imenica ženskoga roda e-vrste.

Iako postoje male razlike, možemo govoriti da je nepoznati autor molitvenika franjevac koji je živio u Budimu i prema nalogu svojih nadređenih morao prevesti

\footnotetext{
${ }^{4} \mathrm{O}$ tome piše Darija Gabrić Bagarić u članku Književnojezična norma franjevačkih pisaca 18. stoljeća. Rasprave Instituta za hrvatski jezik i jezikoslovlje, knj 33 (2007), str. 142

${ }^{5}$ O sinonimiiji u Mikaljinom rječniku pisala je Ljiljana Kolenić (2002) Sinonimi u Mikaljinu rječniku. Riječ: časopis za filologiju, sv.2. Rijeka. 28-33

6 Vidi u Hercigonja, E. (1983) Nad iskonom hrvatske knjige, rasprave o hrvatskoglagoljskom srednjovjekovlju. Liber. Zagreb

${ }^{7}$ Vidjeti kod Hercigonja, E., Nad iskonom hrvatske knjige, Liber, Zagreb, 1983, str. 424
} 
tekst molitvenika s njemačkoga jezika. Prilikom prevođenja poslužio se jezikom franjevačke jezične zajednice koja je dominirala u to vrijeme i koja je neslužbeno već imala obilježja standardnog jezika kojim su se pisala djela ne samo religiozne tematike.

Molitvenik je nastao u sam osvit ilirskog pokreta, a čuva stare jezične oblike podsjećajući na pomno njegovanu jezičnu tradiciju kroz stoljeća.

\section{Literatura}

BATTARA $1847=$ BATTARA Fr. Duxnosti podloxnikah prama njihovu samovladaocu na sluxbu poçétljivih uçilištah. Doveri dei sudditi verso il loro monarca ad uso delle scuole elementari. Izdavanje Perv = Prima Editione. U Zadru, natiskom i troškom Bratje Battara. 1847. 24

BROZOVIĆ 2008 = BROZOVIĆ D. Povijest hrvatskoga književnog i standardnoga jezika. Zagreb, 2008.

DELLA BELLA 1728 = DELLA BELLA A. Istruzioni grammaticali della lingua illirica. (Pretisak 2006., Institut za hrvatski jezik i jezikoslovlje) Zagreb, 1728.

GABRIĆ-BAGARIĆ 1989 = GABRIĆ-BAGARIĆ D. Jezik Ivana Bandulavića, bosanskoga franjevca 17. vijeka. Sarajevo, 1989.

GABRIĆ-BAGARIĆ $2007=$ GABRIĆ-BAGARIĆ D. Književnojezična norma franjevačkih pisaca 18.stoljeća. // Rasprave Instituta za hrvatski jezik i jezikoslovlje, 2007. № 33. 133-145

GABRIĆ-BAGARIĆ $2010=$ GABRIĆ-BAGARIĆ D. Na ishodištu hrvatske leksikografije. Trojezični rječnik Blago jezika slovinskoga Jakova Mikalje 1649./1651. Zagreb, 2010.

HOŠKO 2003 = HOŠKO E. Josip Pavišević - svjedok jozefinizma u Slavoniji i Podunavlju. Zagreb, 2003.

MOGUŠ 2009 = MOGUŠ M. Povijest hrvatskoga književnoga jezika. Zagreb, 2009.

OCZKOWA 2010 = OCZKOWA B. Hrvati i njihov jezik. Zagreb, 2010.

SAMARDŽIJA 2015 = SAMARDŽIJA M. Hrvatski jezik od početka 19. stoljeća do narodnog preporoda // U Povijest hrvatskoga jezika 19. stoljeće, knjiga 4., Zagreb, 2015. 9-35.

ŠUNDALIĆ 2003 = ŠUNDALIĆ Z. Studenac nebeski. Molitvenici u hrvatskoj književnosti od 16. do kraja 18. stoljeća (s posebnim osvrtom na Antuna Kanižlića). Split, 2003.

TAFRA 1985 = TAFRA B. Lanosovićeva „slavonska“ gramatika // Zbornik o Marijanu Lanosoviću, Osijek, 1985. 179-192. 